\title{
The Path and Mechanism of the Influence of Social Capital on Customer Citizenship Behavior in Virtual Community Environment
}

\author{
Hongyu Liu \\ School of Economics and Management, Heilongjiang Bayi Agricultural University, Daqing, China \\ Email: 317945179@qq.com
}

How to cite this paper: Liu, H. Y. (2020). The Path and Mechanism of the Influence of Social Capital on Customer Citizenship Behavior in Virtual Community Environment. American Journal of Industrial and Business Management, 10, 1121-1135. https://doi.org/10.4236/ajibm.2020.106074

Received: May 15, 2020

Accepted: June 7, 2020

Published: June 10, 2020

Copyright $\odot 2020$ by author(s) and Scientific Research Publishing Inc. This work is licensed under the Creative Commons Attribution International License (CC BY 4.0). http://creativecommons.org/licenses/by/4.0/

\begin{abstract}
This paper studies the influence of social capital on customer citizenship behavior in the virtual community environment, and finds out three paths of action. Based on social identity theory, social exchange theory, and social information processing theory, we respectively explain the action mechanism of the three paths, and finally put forward the corresponding management inspiration and strategy.
\end{abstract}

\section{Keywords}

Virtual Community, Social Capital, Customer Citizenship Behavior

\section{Introduction}

With the rapid development of Internet technology, a new type of communication and social group, the "virtual brand community", has sprung up like mushrooms. Different from the traditional way of social communication in the past, the virtual brand community has greatly broken the constraints of time and space, allowing customers from all over the world to participate at any time and any place, providing convenience and possibility for customer interaction. The widespread use of social media has profoundly changed the interpersonal relationship, and it has also changed the relationship between business and customers. Especially during the epidemic at the beginning of 2020, many companies have to use social media to change and maintain relationships with their customers. Therefore, mining and cultivating social capital in virtual communities has become an important way for enterprises to gain competitive advantage. With the rapid growth of online participation, consumers are having an increasingly greater impact on the products and brands they want to buy. Some of the 
participation has positively promoted the development of enterprises. At the same time, there are also many malicious and sloppy remarks that seriously affect the reputation and image of the company, and even lead to losses and bankruptcies. How to motivate the customer to make positive product reviews behavior to improve enterprise competitiveness has become a top priority for enterprise management. And customer citizenship behavior can help companies spread brand-related information, improve brand recognition and reputation, and thus affect the company's revenue. It can be said that customer citizenship behavior can create a competitive advantage.

The existing research on customer citizenship behavior in the virtual community environment mostly explains the formation mechanism of customer citizenship behavior based on social identity theory, but the explanatory power of this mechanism is not enough. At present, the research on the impact of social capital on customer citizenship behavior in the virtual community environment is very lacking. Through the review and combing of the literature, this paper argues that social capital has multiple mechanisms of action on customer citizenship behavior, it has a regulating effect, and it can also act through customer satisfaction and community sensation and customer citizenship behavior.

The research structure of this study is as follows:

First, define two key concepts which are social capital in virtual community and customer citizenship behavior under the virtual community;

Second, sort out the factors that could drive customers to generate virtual community citizenship behavior, which includes individual factors, social factors, and environmental factors;

Third, apply social information processing theory, social exchange theory, and social identity theory to construct the mechanism of the impact of social capital on customer citizenship behavior under virtual community, and build an impact mechanism model;

Finally, form conclusions and management implications.

\section{Definition of the Concept}

\subsection{Virtual Community}

The concept of virtual community was first proposed by American scholar Howard Rigel in 1994. His definition of virtual community is "Social collectives appearing on the Internet, people often discuss and exchange emotions on the same topic, forming a certain network of interpersonal relationships". Rigel believes that a virtual community is an interpersonal relationship network that has a sufficient number of people and allows members to discuss and pay personal emotions on the Internet.

\subsection{Social Capital in Virtual Community}

Williams (2006) pointed out that social capital has a distinction between online and offline categories, and then proposed the concept of Internet social capital. 
Since then, online social capital, online social capital, and virtual social capital have appeared in the literature. Many scholars emphasize that the Internet is suitable for cultivating social capital. The rise of the network makes the revolutionary growth of social capital. This is because that the Internet has the characteristics of openness, borderless, decentralization and diversification, which helps online users to use forums, emails, blogs, Weibo, WeChat, etc. Ways to communicate easily. Mathwick et al. (2007) analyze the social capital in the virtual community environment from a structural perspective, and proves through empirical research that Voluntarism, Reciprocity and Trust affect the formation of virtual community social capital. He also believes that social capital can generate information resources and social support to enhance the value of the virtual community.

A more recognized concept of social capital is the actual or potential collection of resources embedded in the social network relationship structure. The social capital within the virtual community can also be divided into structural, relational, and cognitive social capital (Ellison et al., 2007). In the consumer virtual community, the three types of social capital of customers in the community often appear as interactions with other users in the community, as well as the trust and shared value contained in these relationships. These relationship resources help customers solve problems in the consumption process of product purchase and use, and are often expressed as knowledge sharing and communication between users. The generation of social capital will promote the generation of positive results within the group to avoid negative results, help to improve the efficiency of cooperation, and promote the generation of pro-social behavior, such as knowledge sharing (Chow \& Chan, 2008).

\subsection{Customer Citizenship Behavior in Virtual Community}

Customer citizenship behavior is a voluntary and constructive behavior by customers. Customer civil behavior, as an out-of-role behavior, has a positive impact on the organization and other employees in the organization. For example, customers will share their successful experiences with other customers, treat business employees politely, actively reflect problems to employees, recommend business services to other customers, make service improvement suggestions, and help other customers in the process of providing services. All of these customer citizenship behaviors help promote effective business operations. Therefore, the related research of virtual brand communities in recent years has attracted widespread attention in the field of marketing.

Smith et al. proposed the term "organized citizenship behavior" for the first time in 1983. Since then, considering the particularity of customers in the consumption process, many scholars have proposed the concept of customer citizenship from the perspective of customers. Gruen (1995) uses the concept of organizational citizenship behavior to define customer citizenship behavior. $\mathrm{He}$ believes that customer citizenship behavior is those behaviors that are conducive to corporate organization, have constructive significance and are valued.

The concept of customer citizenship behavior is derived from organizational 
citizenship behavior, which is the behavior that customers take on initiative and voluntarily, which is beneficial to the company to improve service quality and effectiveness (Groth, 2005). The customer citizenship behavior in the virtual community mainly occurs in the consumer virtual community. The users in the community are mostly customers gathered by a certain product, which is expressed by the customers who are willing to make benefits to the community and other users in the community. Behavior includes helping other customers solve problems, actively participating in corporate-led activities in the community, promoting brands, making feedback, etc.

Existing research mainly focuses on why customers would generate citizenship behavior. Bettencourt (1997) finds that customer satisfaction, customer commitment and perceived support are positively correlated with customer citizenship behavior. Gruen et al. (2000) demonstrate that there existed a positive impact of emotional commitment on customer citizenship behavior. Aherne et al. (2005) demonstrate that corporate identity has a positive impact on customer citizenship behavior.

The essence of customer citizenship behavior in the virtual community environment is the interactive form of community participation behavior, which refers to the information sharing practice of customers and other users in the community, and the process of establishing personal identity in the community. This process involves member dual participation of emotions and actual actions, and is influenced by the social environment in which it is located.

We believe that, the premise of customer citizenship behavior includes not only the practical participation factors of self-satisfaction information that have obtained from the virtual community, emotional factors such as the establishment of community identity and the formation of identity in interaction, but also emotional factors of community identity that are established between the identities' interaction. At the same time, the behavior of other members of the community as a community factor also affects their citizenship behavior. Therefore, we consider that the antecedents of customer citizenship behavior include perceiving useful information, virtual community identity and other customers' civic behavior.

Armstrong and Hagel III (1996) argue that the potential economic value of a virtual community stems from the number of participants, frequent use, interactions between users, and the willingness of users to participate in virtual communities. However, these factors require not only the virtual community-led company's support, but also the voluntary behavior of the user to expand the visibility of the community and improve the quality of service in the community. In other words, to explore the potential value of virtual communities, enterprises need to pay attention to the cultivation of customer relationships within the community and develop their citizenship behavior.

Through combing the existing literature, the influence factors of customer citizenship behavior in virtual communities can be classified as community factors, individual factors, and social factors, which can be shown as Figure 1: 


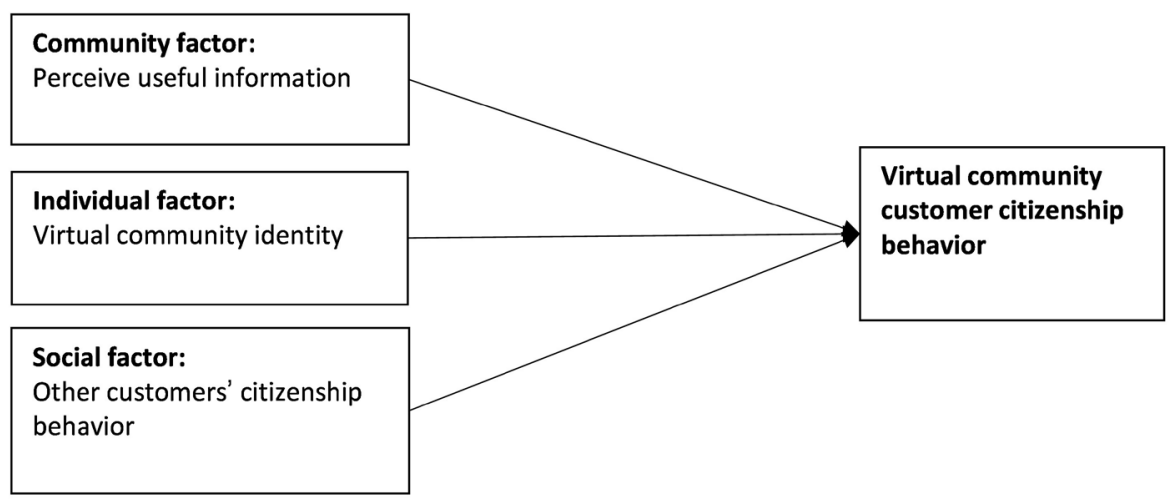

Figure 1. Influencing factors of customer citizenship behavior in virtual communities.

Next, this paper will focus on the social capital of the virtual community, and explore how this virtual relationship resource affects the customer's citizenship behavior through the above three factors. We plan to apply the social exchange theory, social identity theory, and social information processing theory to explain the relevant influence mechanism. According to this theory, an individual makes adjustments or determines his or her behavior by acquiring information about the social environment. In this process, the information provided by the social environment is regarded as a clue, and the more significant it is, the greater the impact on individual decision-making. In a consumer virtual community, the behavior of its users encountered in the service is determined by the customer as a clue to the social environment to determine their own behavior (Eby et al., 2006).

\section{The Relevant Theory}

\subsection{Social Information Processing Theory}

Pfeffer and Salancik (1978) first proposed a theoretical framework for social information processing in the field of job design research. In the field of job design research, SIP theory and needs-satisfaction theory are the two most widely used theories, and scholars use them to explain how the work environment affects employees' various reactions. According to SIP theory, people are an adaptive organism. They adjust their behaviors and change their attitudes based on the external environment, past experience and current situation. A variety of social information, and the different ways people handle it will affect their behavior and attitudes. When people receive social information from the social environment, they will encode, store and explain social information, and finally take corresponding actions. Zalesny and Ford (1990) reviewed the main research based on the SIP framework, and found that the SIP model of Pfeffer and Salancik (1978) and related research based on the SIP model have two theoretical flaws. First, although Salancik and Pfeffer proposed that there are different information processing processes in the relationship between social information and human behavior as mediation mechanisms, but they did not specifically ex- 
plain these mediation processes and did not clearly clarify what the mediation variables are. Second, although many empirical studies based on SIP have explored the regulating factors of the influence of social information, there are relatively few related studies on whether objective environmental factors can regulate the influence of social information on various output factors. Based on the theories of cognition, social judgment, and attribution, Zalesny and Ford (1990) revised the SIP model and elaborated on the three intermediary processes through which social information affects human behavior, namely, the learning process of social information processing, and social information processing attribution process, and the judgment process of social information processing. In addition, they called on future researchers to pay more attention to how various environmental factors regulate the impact of social information on human behavior.

According to the theory of social information processing, individuals as adaptive biological organisms will adjust and change their attitudes, behaviors and beliefs according to the form of social environment to achieve the purpose of adapting to the social environment.

\subsection{Social Exchange Theory}

According to the theory of social exchange, reciprocal norms are the basic moral code, requiring people to have an obligation to return or at least thank those who have helped themselves or his benefit. Rheingold (2000) believes that the spirit of the Internet encourages cooperation and sharing, so that according to the theory of social exchange, reciprocity can be seen as the basic norm of online interaction. In the virtual community environment, social exchange theory is used as a theoretical basis to explain the behavioral motives of people returning to other community members or managers. The basic idea of social exchange is that part of people's behavior is an exchange, and people interact with others in order to get some kind of reward. Because it mainly emphasizes the psychological factors of the person, it is also called the behaviorist social psychology theory. Social exchange theory is an important perspective for studying interpersonal relationships. The theory believes that interpersonal interaction is a process in which participants participate in activities related to each other and exchange valuable resources. The core of the theory is that the relationship between people follows the principle of reciprocity. Exchange remuneration is not only material, but also psychological (such as identification, image maintenance, community influence, and self-efficacy). In the virtual community, the individual is the main body of the virtual community, the individual is the practitioner of the knowledge sharing activity, and the knowledge sharing between individuals is the knowledge exchange between the owner and the requester of knowledge. From the perspective of social theory, knowledge sharing in a virtual community is an individual behavior and an exchange between individuals. The theory of social exchange is helpful to explain the impact of user contribution behavior under 
long-term orientation and focus on long-term common interests.

\subsection{Social Identity Theory}

Tajfel et al. (1971) first proposed the concept of social identity, which refers to the individual's cognitive process of belonging to a social group and the emotional and value meaning brought to him by the group members. Social identity reflects an individual's emotional dependence on a particular social group and the individual's perception of the social status of the group to which it belongs. This theory is widely used in the study of community identity, self-esteem and civic behavior. Social identity is different from personal identity. Personal identity emphasizes self and is an individual concept. And social identification is to find common needs or interests among group members, hoping that they are in line with the group's culture and find their exact positioning. The end result of social identity is to integrate yourself into the group and form some connection with other members of the group. Scholars may define social identity in different dimensions and consider different directions, but they all emphasize the connection between individuals and groups and their emotional belonging to the group. Normally, research on virtual communities incorporates social identity theory. In these researches, social identity, which is also known as community identity or organizational identity, refers to seeing yourself as a member of the community and thinking that you and the community have common characteristics. These characteristics allow individual and group identities to replace each other, and be non-identical. Differentiate the members of the organization. Scholars generally believe that groups in each community will give members positive or negative values, and this will affect the individual's sense of identity in the community. Therefore, every member of the community strives to maintain or even strengthen self-esteem.

\section{The Path and Mechanism of Social Capital's Effect on Customer Citizenship Behavior}

The interaction among the users or consumers in transaction virtual community formed by enterprises is mostly related to answering product-related questions, sharing product use experience and other information or knowledge, participating in corporate interaction activities, giving enterprise product feedback, or participating in the company's product design and so on. The leading companies in the community benefit from this customer-to-customer problem-to-help model and customer feedback, as this can reduce their service costs, quickly capture market demand changes, and generate other valuable by-products (e.g., knowledge, information, social emotional support, etc.). This open and free public resource makes it easy for other community members to create free-riding behavior. Instead of actively participating in the creation of community resources, the lack of public interest will ultimately be passed on to enterprises, hindering the leading companies from benefiting from online virtual communities and 
cutting their weak competitive advantages. Therefore, it is an important path for community-led enterprises to solve the problem of community management by cultivating the virtual community social capital, influencing the subjective will of customers in the community, and then developing its citizenship behavior, acting on the competitiveness of the enterprise. This paper takes this as the research content, focusing on how social capital in the virtual community environment acts on customer citizenship behavior.

Path 1: Acting on customer citizenship behavior through the mediation effect of customer satisfaction

Bettencourt (1997) examined the customer satisfaction has a positive direct impact on the behavior of its citizenship behavior, because he believes customers will appreciate a better experience and to improve the personal satisfaction and goodwill of the enterprise, which will encourage them to make in favor of corporate behavior as others share in the experience or recommend the product to others. A large number of studies have shown that social interaction is positively related to the number of knowledge sharing (Guan et al., 2018; Wasko \& Faraj, 2005; Chiu et al., 2006). Strong interpersonal relationships and frequent interactions help to generate more and more valuable information, thus enhancing the adoption of valuable information and the satisfaction of needs. And the common language in interaction will promote the transmission and understanding of this information more effectively, thus improving customer satisfaction. When customers are satisfied with the services of the company or feel that they have received extra treatment that exceeds their expectations in the context of online shopping malls, applying on the theory of social exchange, they will be more inclined to learn from the citizenship behavior in return. Although customers' satisfaction has a significant impact on customer citizenship behavior in an online shopping environment. Cheng \& Wu (2017) verifies that virtual social capital will affect the satisfaction of online shopping consumers and their loyalty to the brand.

For consumers, the social capital that exists in consumer virtual communities can generate more valuable information due to frequent contact interactions, which can help customers choose suitable products or solve problems in the use of goods. The mutual trust among the customers can not only help them believe in the reliability of information and thus increase the consumer satisfaction; and the common language in communication can help each other better understand the problem to be solved, and can also enhance the pleasure of the communication process and further improve the customer's satisfaction. This satisfaction is not only reflected in the customer's satisfaction with the help of other community members, but also improves the satisfaction of the community management and the good impression of the overall image of the company as the problem is solved in a timely manner, thereby improving his subjective willingness to return to others and the community.

According to the theory of social exchange, a customer's good experience will be rewarded by making things that benefit the community. The higher the cre- 
dibility of the relationship in the community, the more likely it is to adopt other users' opinions. At the same time, other customers also would be more willing to share real personal experience to help others, thus promoting the emergence of citizen behavior.

Path 2: Acting on customer citizenship behavior through the sense of virtual community mediation effect

The concept of virtual community perception stems from the sense of community in community psychology. McMillan and Chavis (1986) defined community perception as a sense of membership, belonging, identity, and attachment to individuals. This concept has also been widely recognized and applied by scholars. Similarly, there is a sense of community in the virtual community environment and has received widespread attention from scholars.

Blanchard and Markus (2004) applied the theory of McMillan and Chavis's sense of community to the virtual community environment, and found that there is also a sense of membership and identity in the virtual community environment, but there is a difference between the sense of the offline community. They believe that the reason for this difference is that the interaction of the virtual community is mostly anonymous communication, and members pay more attention to the similarity and authenticity of the other party.

For this reason, unlike previous studies, this paper argues that the three dimensions of social capital of consumer virtual communities do not directly affect the sense of virtual community. Structured social capital promotes cognitive and relational capital. And the increase in cognitive and relational capital will promote the sense of virtual community.

Kwan and Skoric's (2013) research found that the use of social media is positively correlated with being cheated and injured. In the virtual community environment, interpersonal relationships of the members are expressed as symbols relationship, and the members do not necessarily know each other true identity. The interaction between the customer and other members does not necessarily bring benefits, and it is not because of frequent participation in community activities. And there is a tendency to rely on the community. Frequent interactions help to resonate and trust customers. For example, in an interaction, customers may resonate with the same problem or similar shopping experience in product use and share their true consumption. Experience has enhanced mutual trust. According to the theory of social identity, if an individual shares a common value in the community, then the person will think that he and other members of the community are members of the group and have a sense of belonging to the community. At the same time, these interactions help to increase mutual trust. When trust relationships are established among members, people are more willing to participate in the cooperative interaction of the community by spending a lot of time and energy. When individuals see themselves as members of a group, they are emotionally involved in the group and show pro-social behavior within the group, and social trust also leads to the benefit of the community and contribute to the behavior of others $(\mathrm{Wu}, 2020)$. 
Path 3: Social capital plays a regulatory role in the influence of other users' citizenship behavior on the customer's citizenship behavior

Existing literature of community research have proved the positive promotion of social capital and the role of avoiding negative effects, such as reducing crime rate, on helping others, knowledge sharing, community contribution and other pro-social behaviors (Wasko \& Faraj, 2005). Krämer et al. (2014) found that the strength of relationships in social networks has an impact on emotional support and information support. Liu et al. (2014) take the social capital in the virtual community as the research object, empirically studies the influence of social capital on the contribution of individual knowledge, and finds that the prestige mechanism of the community has a regulatory effect on the relationship between the two.

According to the theory of social information processing, as parts of the social environment, other users in the community can affect the customers through their behavior method and degree. If customers see other users in the community exhibit civic behavior, they may think that this behavior is normal, acceptable, or even worth imitating, so that they may be encouraged to exhibit similar civic behavior. Bearden \& Etzel (1982) think that the higher the credibility of the information and the higher the credibility of the source, more likely to be adopted by consumers. In other words, the influence of other users' behavior on customers will be regulated by trust and cognition. When customers consider other users to be trustworthy and share common perceptions and preferences, other users' information (that is, their citizenship behavior) will more effectively influence customer attitudes and behaviors. It can be said that the virtual community social capital will positively regulate the impact of community user citizenship behavior on consumer citizenship behavior.

Based on the above analysis, this study complies with social identity theory, social exchange theory, and social information processing theory, and analyzes the relevant self-acting mechanisms of social capital on customer citizenship behavior in a virtual community environment, and constructs the impact of virtual community social capital on customer citizenship behavior model, as shown in Figure 2.

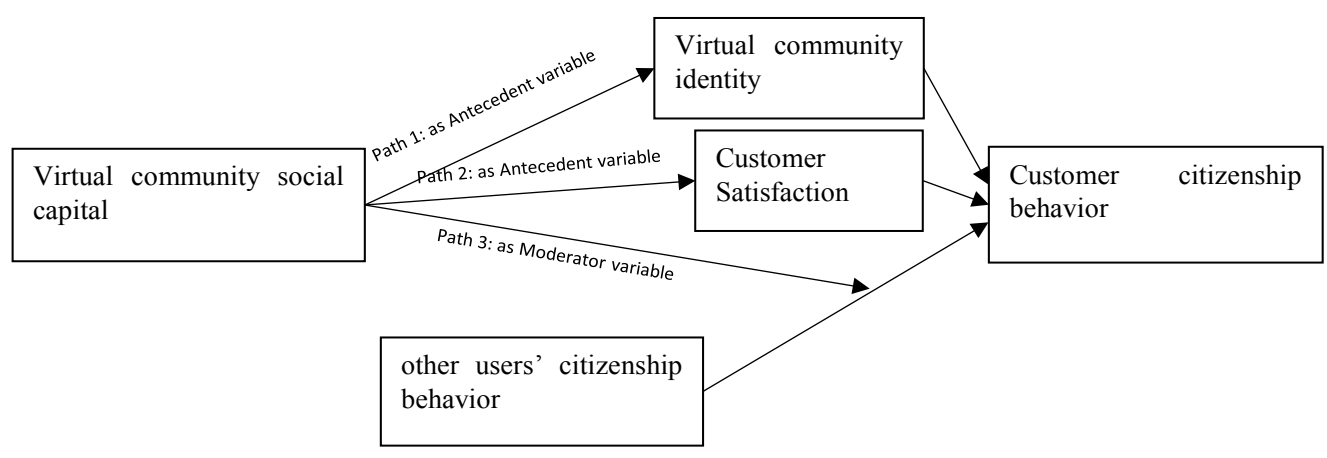

Figure 2. Research model of the impact of social capital on customer citizenship behavior in virtual community. 


\section{Discussion and Implications}

\subsection{Conclusion}

The purpose of this article is to explore the impact of social capital on citizen behavior in a virtual community environment. Based on the existing research, this research focuses on the customer citizenship behavior of the consumer virtual community, and attempts to establish the relationship between social capital and customer citizenship behavior. By analyzing the antecedents of customer citizenship behavior, we found that the impact of social capital on customer citizenship behavior is multi-path rather than single-path, that is, social capital will act on customer citizenship behavior through customer satisfaction and virtual community sense, and will regulate the impact of other customer citizenship behaviors on that customer citizenship behavior. And last we use social identification theory, social exchange theory, and social information processing theory to explain the mechanism of action under the three paths. At the same time, this paper finds that in the process of forming the sense of the virtual community, the structure, relationship, and cognitive dimension of social capital are not all parallel, but the structural element dimension first acts on the relationship and cognitive factor dimensions. The actor then acts on customer citizenship through a virtual community sense. The research results of this paper to some extent make up for the research on the antecedents of customer citizenship behavior in the virtual community environment to some extent, and also enrich the study of the mechanism of social capital on customer citizenship behavior, which has certain theoretical significance.

\subsection{Implications for Practice}

The generation of customer citizenship behaviors plays an important role in the development of enterprises. As an important corporate asset, customer assets are beneficial to the operation and long-term development of enterprises. Therefore, it is of practical significance to study the influencing factors of customer citizenship behaviors.

Citizenship in virtual communities is seen as one of the main factors that sustains the success of the community. How to inspire the citizens' behavior in the community has become an important task for community managers and corporate managers. An important purpose for enterprises to develop and operate virtual communities is to cultivate and tap social capital. It is of great practical significance to use these resources to stimulate customer citizenship behavior.

1) Enterprises that lead the community should inspire a higher reputation and highly-respected users in the community to participate in community activities, make more statements that are beneficial to the enterprise, and help other customers solve problems, especially in motivating community opinion leaders' citizenship. Opinion leaders have a significant impact on the company's marketing and operations. Nowadays, consumers are more inclined to believe in information from social sources based on interpersonal interactions, rather than 
business information published by businesses; from the perspective of influence generation process, opinion leaders occupy a central position in social networks (including virtual communities) and groups. Their behavior will play an exemplary role and affect the enthusiasm of other customers for citizen behavior. At the same time, we must resolutely curb the occurrence of defeat. The leading companies in virtual communities can enhance the sense of belonging and superiority of users by comparing the differences between members inside and outside the community, thereby further enhancing their sense of identity to the community of interest, so as to enhance the user's willingness to use and promote the user's continued use. First, identifying the main body of opinion leaders in the community is a key step. And then community managers need to build frequent interactions with opinion leaders. Even they should form opinion leaders as the community's social capital. And community managers can also work with opinion leaders to develop community activity plans, and gives opinion leaders additional participation rewards.

2) The leading companies in virtual communities should establish a reasonable incentive mechanism for user behavior. To encourage interaction among customers in the community, increase the opportunity and frequency of communication between customers, timely response to customer questions will increase their satisfaction and community recognition, and an increase in the frequency of interaction between customers will increase customer response. The sense of belonging of the community, customers will also increase the initiative and willingness to participate in interaction. Community managers should actively respond to and encourage user contributions to increase the enthusiasm and initiative of members in the community. At the same time, feedback can increase the recognition and emotional communication between users. The only form of feedback that likes is too simple, so you can add a rating mode, which can have positive and negative feedback. The image maintenance largely shows the status of users in the community. The community manager can use the user's contribution in the community to give rise to the level and give them different rights for different levels. This will help stimulate users to generate stronger Sense of community identity and was inspired by more pro-community behaviors.

3) Enterprises that lead the community should pay attention to the development and use of common language. This will not only help customers to express their understanding of product consumption and use of existing problems, but also allow community members to accurately understand the meaning of the expressions and give solutions to problems. Degree stimulates citizen behavior. At the same time, the use of these common languages will enhance customers' sense of community recognition, which will increase the sense of responsibility towards the community and help promote the pro-community behavior.

4) In order to improve the social presence felt by users in the process of virtual community communication, community-led enterprises can use technology to display the screen sense of the web page to make the content look fuller or use 
interactive multimedia tools with functional products, which Citizenship that inspires users to make a positive contribution to the community. We should pay attention to the multiple aspects of social presence. Social presence induction should be enhanced through the use of emotional representations, so that users have a sense of belonging and immersion. Social agents can also be used to enhance users' understanding of the products or services provided by the community through the interactive content and methods of social agents. Social presence is not just about Internet technology issues and communication media. In community management, we should pay more attention to the presence of communities in order to realize more value.

\subsection{Limitations}

There are still many deficiencies in this research. First, this study establishes a mechanism model of the impact of social capital in virtual communities on customer citizenship behavior, but due to resource and time constraints, the model has not been verified through empirical research. At the same time, this article has not yet carried out an in-depth analysis of the three dimensions of social capital under virtual communities, namely structural capital, relational capital, and cognitive capital, on the impact mechanism of customer civic behavior. These deficiencies will also become the main direction of follow-up research.

\section{Acknowledgements}

This work was supported by Heilongjiang Bayi Agricultural university science training project under grant number RRCPY201804, and supported by Heilongjiang Bayi Agricultural University PhD Talent Scientific Research Support Project under grant number XDB201810.

\section{Conflicts of Interest}

The author declares no conflicts of interest regarding the publication of this paper.

\section{References}

Aherne, M., Bhattacharya, C. B., \& Gruen, T. (2005). Antecedents and Consequences of Customer-Company Identification: Expanding the Role of Relationship Marketing. Journal of Applied Psychology, 90, 574-585. https://doi.org/10.1037/0021-9010.90.3.574

Armstrong, A., \& Hagel III, J. (1996). The Real Value of ON-LINE Communities. Harvard Business Review, 74, 134-141.

Bearden, W., \& Etzel, M. J. (1982). Reference Group Influence on Product and Brand Purchase Decisions. Journal of Consumer Research, 9, 183-194. https://doi.org/10.1086/208911

Bettencourt, L. A. (1997). Customer Voluntary Performance: Customers as Partners in Service Delivery. Journal of Retailing, 73, 383-406. https://doi.org/10.1016/S0022-4359(97)90024-5

Blanchard, A., \& Markus, M. (2004). The Experienced "Sense" of a Virtual Community: 
Characteristics and Processes. ACM SIGMIS Database, 3, 64-79.

https://doi.org/10.1145/968464.968470

Cheng, Z.-C., \& Wu, Y. B. (2017). The Effects of Knowledge Sharing on User Stickiness in Virtual Communities Based on Social Capital Theory. Information Science, 35, 16-21.

Chiu, C. M., Hsu, M. H., \& Wang, E. T. (2006). Understanding Knowledge Sharing in Virtual Communities: An Integration of Social Capital and Social Cognitive Theories. Decision Support Systems, 42, 1872-1888. https://doi.org/10.1016/j.dss.2006.04.001

Chow, W. S., \& Chan, L. S. (2008). Social Network, Social Trust and Shared Goals in Organizational Knowledge Sharing. Information \& Management, 45, 458-465. https://doi.org/10.1016/j.im.2008.06.007

Eby, L. T., Lockwood, A. L., \& Butts, M. (2006). Perceived Support for Mentoring: A Multiple Perspectives Approach. Journal of Vocational Behavior, 68, 267-291. https://doi.org/10.1016/j.jvb.2005.07.003

Ellison, N. B., Steinfield, C., \& Lampe, C. (2007). The Benefits of Facebook "Friends": Social Capital and College Students' Use of Online Social Network Sites. Journal of Computer Mediated Communication, 12, 1143-1168. https://doi.org/10.1111/j.1083-6101.2007.00367.x

Groth, M. (2005). Customers as Good Soldiers: Examining Citizenship Behaviors in Internet Service Deliveries. Journal of Management, 31, 7-27. https://doi.org/10.1177/0149206304271375

Gruen, T. W. (1995). The Outcome Set of Relationship Marketing in Consumer Markets. International Business Review, 4, 447-469. https://doi.org/10.1016/0969-5931(95)00026-7

Gruen, T. W., Summers, J. O., \& Acito, F. (2000). Relationship Marketing Activities, Commitment, and Membership Behaviors in Professional Associations. Journal of Marketing, 64, 34-49. https://doi.org/10.1509/jmkg.64.3.34.18030

Guan, X.-H., Xie, L. S., \& Huan, T.-C. (2018). Customer Knowledge Sharing, Creativity and Value Co-Creation: A Triad Model of Hotels, Corporate Sales Employees and Their Customers. International Journal of Contemporary Hospitality Management, 30, 961-979. https://doi.org/10.1108/IJCHM-09-2016-0539

Krämer, N. C., Rösner, L., Eimler, S., Winter, S., \& Neubaum, G. (2014). Let the Weakest Link Go! Empirical Explorations on the Relative Importance of Weak and Strong Ties on Social Networking Sites. Societies, 4, 785-809. https://doi.org/10.3390/soc4040785

Kwan, G. C., \& Skoric, M. M. (2013). Facebook Bullying: An Extension of Battles in School. Computers in Human Behavior, 29, 16-25. https://doi.org/10.1016/j.chb.2012.07.014

Liu, H. X., Liu, R. J., \& Li, G. Q. (2014). Research on the Relationship among Social Capital, Information Technology and Knowledge Contribution: An Empirical Analysis Based on Firm-Hosted Virtual Community. Management Review, 26, 10-19.

Mathwick, C., Wiertz, C., \& De Ruyter, K. (2007). Social Capital Production in a Virtual P3 Community. Journal of Consumer Research, 34, 832-849.

https://doi.org/10.1086/523291

McMillan, D. W., \& Chavis, D. M. (1986). Sense of Community: A Definition and Theory. Journal of Community Psychology, 14, 6-23. https://doi.org/10.1002/1520-6629(198601)14:1<6::AID-JCOP2290140103>3.0.CO;2-I

Pfeffer, J., \& Salancik, G. R. (1978). Organization Design: The Case for a Coalitional Model of Organizations. Organizational Dynamics, 6, 15-29. https://doi.org/10.1016/0090-2616(77)90043-2 
Rheingold, H. (2000). Tools for Thought: The History and Future of Mind-Expanding Technology. Cambridge: MIT Press.

Smith, C. A., Organ, D. W., \& Near, J. P. (1983). Organizational Citizenship Behavior: Its nature and Antecedents. Journal of Applied Psychology, 68, 653-663. https://doi.org/10.1037/0021-9010.68.4.653

Tajfel, H., Billig, M. G., \& Bundy, R. P. (1971). Social Categorization and Intergroup Behaviour. European Journal of Social Psychology, 1, 149-178. https://doi.org/10.1002/ejsp.2420010202

Wasko, M. M., \& Faraj, S. (2005). Why Should I Share? Examining Social Capital and Knowledge Contribution in Electronic Networks of Practice. MIS Quarterly, 29, 35-57. https://doi.org/10.2307/25148667

Williams, D. (2006). On and Off the Net: Scales for Social Capital in an Online Era. Journal of Computer-Mediated Communication, 11, 593-628. https://doi.org/10.1111/j.1083-6101.2006.00029.x

Wu, L., \& Liu, J. (2020). Need for Control May Motivate Consumers to Approach Digital Products: A Social Media Advertising Study. Electronic Commerce Research, 173-188. https://doi.org/10.1007/s10660-020-09399-Z

Zalesny, M. D., \& Ford, J. K. (1990). Extending the Social Information Processing Perspective: New Links to Attitudes, Behaviors, and Perceptions. Organizational Behavior and Decision Processes, 47, 205-246. https://doi.org/10.1016/0749-5978(90)90037-A 